\title{
The Effect of Aesthetics on Web Credibility
}

\author{
Farah Alsudani \\ Department of Computing \\ University of Surrey \\ Guildford, Surrey GU2 7XH UK \\ +44 (0) 1483689635 \\ farasudani@yahoo.com
}

\author{
Matthew Casey \\ Department of Computing \\ University of Surrey \\ Guildford, Surrey GU2 7XH UK \\ +44 (0) 1483689635 \\ M.Casey@surrey.ac.uk
}

\begin{abstract}
Credibility influences a user's interest in a web site. Once users perceive the credibility of a web site they will be more likely to use it. A combination of factors affects such credibility - such as the provider, content, aesthetics, accessibility and solution of technical problems. The aesthetics of a web site can affect a user's first impressions of credibility. Experiments have shown that users can judge a web site's credibility in as little as 3.42 seconds merely on the basis of its aesthetic appeal. But what are the aesthetic factors that influence immediate judgment on web credibility? A study was conducted to ascertain these factors; first a framework of factors was suggested to develop a method focusing on the users' actual perceptions in judging credibility based on aesthetics. This was done with 30 subjects viewing 13 pairs of images of recruitment agency web sites. 'Unity' in design with its elements of balance, harmony, contrast and dominance was found to be an effective aesthetic factor resulting in immediate judgments on web credibility. These factors were presented for beginner web designers in online tutorials. This work is a result of MSc project.
\end{abstract}

\section{Categories and Subject Descriptors}

H.5.2 User Interface

\section{General Terms}

Human Factors, Design

\section{Keywords \\ Credibility, Aesthetics, Gestalt Theory, Unity.}

\section{INTRODUCTION}

First impressions of viewing a web site's home page affect a user's decision as whether to continue viewing that web site or move to another one. This decision can be made in as little as 50 milliseconds mainly because of the page's visual appeal [17]. First impressions affect users' judgments on different aspects of web site design including usability, credibility or purchasing intentions [28]. As the content of a web site is what matters most to its users, the more this content is considered credible the more this web site will be used [7], thus first

(c) The Author 2009.

Published by the British Computer Society impressions of a web site's credibility is critical as it will affect its success. Some of these first impressions are based on surface credibility which corresponds to the web site's appearance: appealing, professional or disturbing, the web site's provider or famous citations [5], plus its accessibility and the amount of advertisements it has [15]. Recent studies have shown that judgments on web site credibility are $75 \%$ based on a web site's overall aesthetics [6], and these judgments are immediate as they occur as fast as 3.42 seconds [21]. But what aesthetic factors are responsible for the immediate judgment on web credibility? In this paper, for the first time we attempt to provide and evaluate some of these aesthetic credibility factors for home pages, which should be designed differently from the interior pages [19]. This does not diminish the role of other web factors that affect credibility such as the provider, content, technical accuracy [5] and accessibility [15], but we are highlighting the immediate effect that such aesthetics have on credibility, and particularly surface credibility [5].

To achieve our aim we conducted an extensive review to develop a framework for web aesthetics factors. This framework was developed by applying art and design concepts and practices into computing [4]. A further challenge was to find a systematic method for appraising web aesthetics [25] because aesthetics are subjective and cannot be quantified for correctness due to human involvement [16], thus this study developed a method based on the framework of web aesthetics factors developed by our study. This method allows us to test credibility in a systematic way, by depending on actual users' interactive perceptions to appraise some web aesthetics factors and evaluate their effect on web credibility. Then, the factors gained from applying this method were tested by reapplying the same method to verify their validity. The main motivation behind our study is to promote web credibility, by enhancing one of the factors that affects it which is aesthetics. Our study attempts to fill the gap in the HCI literature about web credibility and aesthetics as web functionality and usability are always the focus rather than credibility or aesthetics [14], we also aim to enhance the interaction between the user and the web page [4] through aesthetics. From a web design perspective, our suggested framework of web aesthetics factors is an attempt to aid web designers in their design phase who have a need for theoretical and systematic methods to analyse web design factors [2]. All this will eventually promote the technical aspects in web site design and enhance usage and success of web sites, helping designers and their business clients to increase business, but we must emphasise that web design is a creative field which rules or guidelines are helpful but non restrictive. 


\section{WEB AESTHETICS FACTORS}

There is a significant lack of any theoretical framework for web aesthetics factors [2]. Rather, two different frameworks were identified: the first looks at a web page as pure individual factors like colour, typography, design, pictures, video clips, flash animation and sound [26]. Tidwell [27] discusses more specific individual factors - spaciousness and crowding, angles and curves, texture and rhythm, cultural references and repeated visual motifs and images, while forms, buttons, search features, frames and page length are discussed in ISO (9241151) [8].

The second framework looks at a web page as relationships between individual elements that form the whole visual composition of a web page. This framework is mainly based on human factors provided by Gestalt psychology $[1,9]$ which is concerned with the entity as a whole rather than what it is formed from. Psychologists like Arnheim argue that people perceive something as a whole not a number of individual elements. That is to say, people perceive things as compositional objects, and the main importance is the form of that visual composition itself rather than its individual elements [1].

Accordingly, recent studies in the web field like Schenkamn, and Jönsson [22], concluded that users form their first impressions of web sites based on the overall visual appearance, rather than on a particular element. Similarly, studies in aesthetic computing [4] and interface design [2] have highlighted the importance of relationships in design. For example, Park, Choi \& Kim [20] aimed to identify the visual elements of a home page by evaluating a home page as a combination of relationships between individual objects, where objects are organised according to Gestalt's patterns of similarity, proximity, continuity and closure [27] to form a web page of relationships of balance, symmetry, movement, rhythm, contrast, proportion, unity, simplicity, density, regularity and cohesion composing the overall page layout. Although that study is based on the human factor foundation of Gestalt theory $[1,9]$, it did not acknowledge that the relationships are basic art and design concepts [23] which apply to every artistic composition including web visual design. Also objects in this study [20] were not clearly identified, as many explicitly perceived objects were not considered, such as images, texts, spaces, menus, logos, multimedia objects, etc. Object attributes were also treated more generally such as through size, colour and location only. Crucially they considered 'Unity' as a relationship like any other [20], rather than considering it as an ultimate relationship where some or all other relationships cooperate to achieve it [23]. Here we use Lauer's [13] definition for 'Unity' as it is the visual association of objects which leads them to be perceived as a single unit. This reveals that the argument of Park, Choi and Kim [20] for web aesthetics factors has misconnected the human factor of Gestalt theory to their framework. According to Shirzad [23] 'Unity' is cohesion, as cohesion is responsible for keeping elements related together to form a unified composition that represents the designer's concept behind it. Similarly for Landa [12] 'Unity' allows the viewer to see the parts related and integrated as a whole - this is the target of any composition design. Also, for White [29] 'Unity' enables elements of design to look like they belong together. So we cannot treat 'Unity' as a separate relationship.
Ultimately, neither of the frameworks described above can be adopted on its own. Because the first framework evaluates a web page as individual objects but without consideration to any human factor which is essential in any interactive system, while the second framework evaluates a web page as relationships between the objects considering the human foundation of Gestalt theory [1, 11], but it failed in applying that human factor into web aesthetics. Hence, neither identifies aesthetic objects of a web page fully and explicitly. Instead we treat 'Unity' as a unified unit where all components cooperate to achieve, and are responsible for the visual appeal [12, 23, 29], and apply this to home page first and to the web site as a whole then. Our evaluation uses the framework provided in Figure 1.

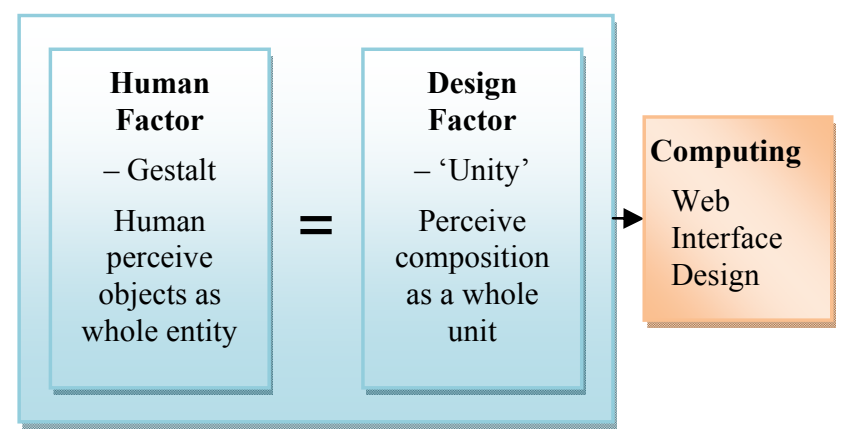

\section{Figure 1. Foundation for Suggested Web Interface Design}

We use this idea to develop a framework consisting of basic design concepts, organisational concepts (including identicality and discord [23] which are rarely discussed) and relational concepts (including harmony, gradation, repetition and dominance [23] where the latter is rarely discussed) (see Figure 2).

This framework of web aesthetics factors considers the human as the central part in the design phase, by adopting the foundation of Gestal theory $[1,11]$. As it can been seen in Figure 2, there are objects which include any figures and/or backgrounds in the web page, where each object has specific attributes that depend on its nature. For example, an icon is an object where size, shape, colour border thickness/colour, location, resolution and texture can be considered as its attributes. Objects are organised according to organisational patterns composing entities, which are related by relationships to form a whole unit which is ultimately the web page. 'Unity' will depend on the relationships between the way objects and their attributes are organised, through a web page and the whole web site.

\section{WEB AESTHETICS APPRAISAL}

As illustrated earlier, the credibility of a website is often based on its aesthetic appeal, a characteristic that is almost impossible to quantify due to its highly subjective nature [16]. For that, to start evaluating what web aesthetics factors affect instant judgments on credibility, we were unable to discover an explicit and systematic method using predictive metrics to evaluate website aesthetics [25]. The mathematical based method for measuring web aesthetics devised by Ngo and Byrne [18], which utilised some algorithmic rules to evaluate web aesthetics, has been considered although not without controversy; King [10] emphasised that it is 


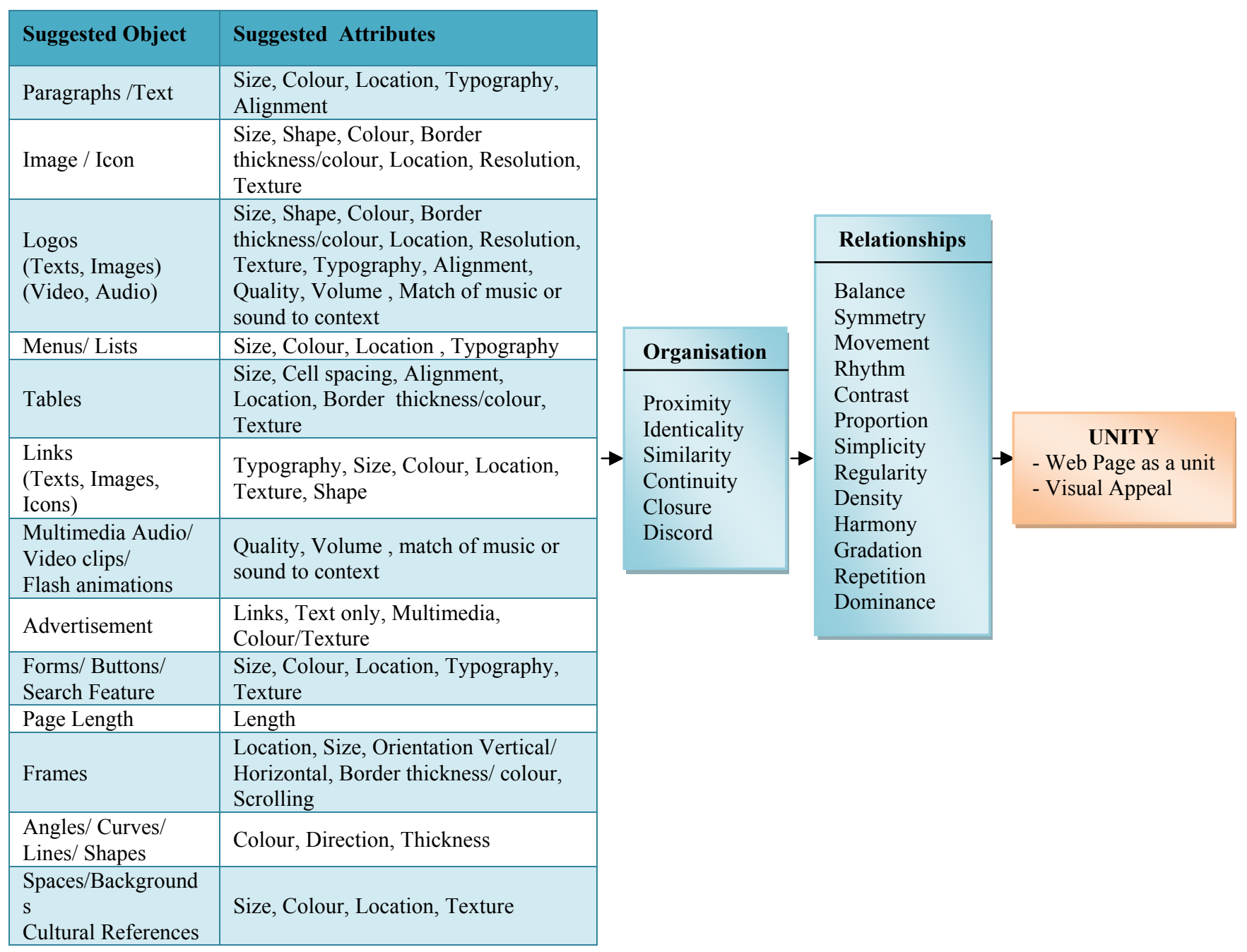

Figure 2. Suggested Framework for Web Aesthetics Factors

totally impossible to develop a mathematical theory to measure aesthetics, also Tidwell [27: xvi] argued that "good design can't be reduced to a recipe". In the light of this, our study believes that aesthetics is a practice where human perception is highly involved, which leads us to depend on humans in order to evaluate aesthetics by developing an interactive method to appraise web aesthetics to judge credibility on an aesthetic basis.

\subsection{Method}

As discussed earlier, 'Unity' enables compositions to be perceived as a whole $[12,23,29]$. Thus it is the initial and most important relationship in design that other relationships cooperate together to achieve. As one of the foundations for our method is the application of design concepts (see section 2), thus from a design perspective, all relationships presented in Figure 2 cooperate to achieve 'Unity'; in fact separating them is not valid from a design perspective and that is exactly what makes studying aesthetics difficult. We will discuss how to achieve 'Unity' which is responsible for the attractive visual appeal of the web site as a whole by applying the relationships of balance, harmony, contrast and dominance only, as these are the basic relationships to achieve 'Unity' [23], and have rarely been discussed before from a pure art and design perspective, but we will discuss how to achieve 'Unity' in a home page only to achieve our study's main aim.
Balance is defined as the equal distribution of optical weight [12] - the optical weight refers to the influence of the attributes of size, colour and location for some objects. There are two kinds of balance, formal and informal. Formal balance is the symmetrical balance of similar or identical objects organised on an axis [12, 23], as depicted in the similar three adjacent rounded rectangles in Figure 3. Informal balance is the asymmetrical balance of different objects organised on an axis $[12,23]$ as in the two entities embraced in the dashed rectangles in Figure 3.

Harmony is the match between different attributes of objects like colour, size, shape, typography or texture [23], like the harmony between colour attributes of all objects of the web page in Figure 3. In this study only the harmony of different colours will be discussed [23].

From a design perspective, balance and harmony are aesthetically comfortable to the eyes but a web page needs more than this to attract attention, such as contrast, which adds life to the design, makes it more interesting and eliminates a boring or dull design $[9,23]$. Although contrast is the difference between objects' attributes like colour and size [9, 23], this study will discuss colour contrast only, like the contrast between the colours of the buildings in Figure 3 and the colours of all other surrounding objects. This obvious contrast has 


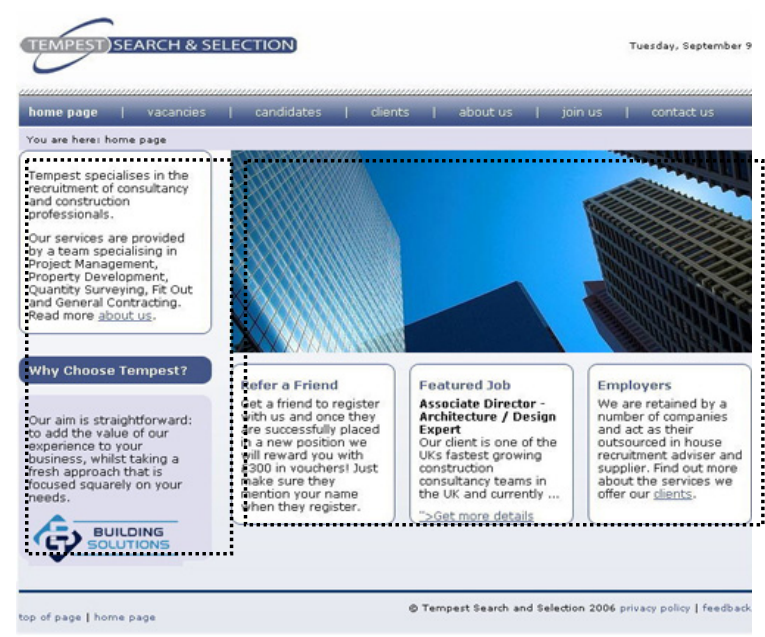

Figure 3. Home Page of 'Unity' in Design

created a strong and recognisable feature in this web page. This is known as dominance in which one element in a web page is considerably more perceived than other elements [9, 23, 29]; in fact all the other elements combine to highlight the dominant colours of the image in Figure 3. The concept of dominance can be clearly found and understood in a play or a movie that has one or two dominant roles while the other roles support these, dominant roles catch audience's attention all the time; this is similar to dominance in design as it generally catches attention [23]. Dominance can be achieved by contrast like the dominance of a considerably larger object [23, 29]. Although the web page in Figure 3 shows an example of dominance by size of image, it also shows a dominant contrast between the image and surrounding colours achieving what can be called as dominance by contrast. This shows an overlap between the two kinds of dominance that are discussed in this study. As we mentioned earlier our study presents the concept of dominance as it has rarely been presented. It must be noted, however, that the web designer decides which objects and attributes to make dominant in response to his/her concept behind the design.

Our study considers balance and harmony as the minimum requirements for 'Unity' [3, 23], while adding contrast or dominance can achieve an attractive 'Unity' $[9,23]$ as applied in Figure 3. Therefore, it is argued that users' first impressions of web aesthetics are formed by balance, harmony, contrast and dominance which all achieve a form of unity in design, responsible for the visual appeal.

\subsection{Stimuli}

Home pages of recruitment agency websites were selected for the stimuli as their credibility is important for their users. It is worth pointing out here that most of the studies in the HCI field have focused on e-commerce web sites or educational web sites, rather than on any other kind. So, lesser known recruitment web sites were chosen to eliminate the chance of being recognised by a subject resulting in biased perceptions. Only home pages of these websites were selected rather than other pages, so subjects' first impressions will judge a website's credibility based on its home page. Images of the home pages were prepared in 13 pairs. Each pair of images examines one of the relationships of balance, harmony, contrast/dominance by contrast and dominance by size for some objects. For example, the pair shown in Figure 4 examines contrast/dominance by contrast via the use of colour for the CTR logo. Each pair contains two images of exactly the same content where one image is the original live home page (Figure 4A), while the other image (Figure 4B) is modified in response to our method by changing the logo's colour from blue to grey, to make image A more attractive than $\mathrm{B}$ due to the strong contrast it has with the blue colour against the white background. Image B has been deliberately made less attractive than A by having a weaker contrast between the grey colour of the logo against the white background. To ensure fair perceptions, it is only the elements of contrast/dominance by contrast which are evaluated in that pair - all other elements, such as harmony, balance and dominance by size, have not been altered and that is how all pairs are evaluated through this study. Home pages were selected assuming that their loading time is fast, their animation is static and their page is shown without the need for a vertical or horizontal scroll bar.

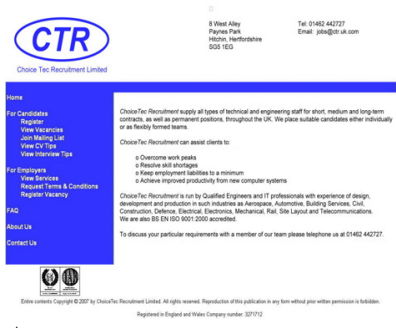

A

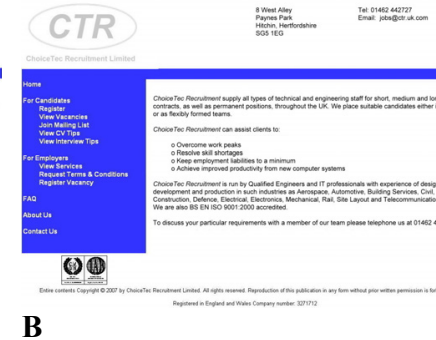

B
Figure 4. Pair 6 Stimuli Investigating Contrast/ Dominance by Contrast

\subsection{Subjects}

30 people were selected to judge credibility; subjects were of a balanced gender: 15 males and 15 females to assure fair results with respect to any differences in gender-based perception. Adult subjects aged between $18-40$ were chosen as it has been shown that under $18 \mathrm{~s}$ are much quicker at perceiving content details of websites than adults [28]. It is a requirement for this study that credibility is not judged on the content so under $18 \mathrm{~s}$ have been excluded from the sample. The subjects chosen were all university students. Only one of the subjects was a professional web designer who was also a student, while the rest had no knowledge or experience in that field.

\subsection{Apparatus}

Ulead PhotoImpact 10 and Adobe Photoshop CS2 were used for image preparation, while Microsoft Access 2003 was used to build a program to view the stimuli and save subjects' perceptions in a database for evaluation. A laptop of $1.73 \mathrm{GHz}$ CPU and $1.73 \mathrm{GHz}, 0.99 \mathrm{~GB}$ of RAM was used to run the stimuli during the interviews.

\subsection{Procedure}

Subjects viewed the stimuli in an interview rather than in an offline survey, because it is believed that more reliable perceptions can be gained in interviews [21]. It was discovered that individual interviews motivated the subjects to participate and take the activity more seriously than if it had been conducted through offline surveys. It was also important to discover subjects who encountered difficulties, or who lacked interest, and thereby flag up their results for further consideration. Silent locations also helped to promote better concentration.

The subjects for the purposes of this study were to assume they were looking for a job and seeking recruitment agency web sites. They were asked to judge the credibility of the websites 
based on their first impressions by viewing home pages of the website for 3.42 seconds only, to examine aesthetic factors if any were responsible for instant judgment on credibility. The pages would be shown only once. No mention was made of the aesthetics of stimuli to avoid any bias.

To let subjects adjust to the viewing speed, and to train themselves to catch the difference between the images in each pair, an example was shown to them of a pair of images which could be viewed for 3.42 seconds only. This example could be repeated as many times as the subjects wanted until they felt they were ready to start judging the actual stimuli. This 'training' example also acted as a subject filter - some subjects were able to grasp what was required and quick enough in perceiving differences between images in the pair, while others either found it very fast or got adjusted to the speed but at the same time were unable to catch any difference. In the latter cases they were thanked and did not continue judging credibility. Again, this underlines the importance of the interview rather than an offline survey in gaining reliable results.

Once subjects were confident with the example they began judging credibility. They viewed the 13 pairs of stimuli and chose one image that they judged as being more credible in each pair, justifying their choice. Subjects were told that if they were unable to make a selection, then they were prompted not to choose either image in a pair. This was an inconclusive result (referred to as 'None' in Table 1). After each 13 pairs were shown, subjects had the opportunity to take a break to clear their mind and rest their eyes to restart focusing on the next pair once they are ready. After that and without a time limit, subjects answered a time free questionnaire which was accompanied by the same images of the web pages viewed in the interview. This was used to examine more precisely the appreciation of each relationship.

\subsection{Results}

From the rapid display of the 13 pairs of stimuli, 30 perceptions were collected for each evaluated relationship: balance, harmony, contrast/dominance by contrast and dominance by size. The mode of these perceptions was calculated to produce the results as illustrated in Table 1 (repetitive relationships correspond to the evaluation of different objects or different attributes). As can be understood from Table 1, relationships of contrast and dominance by contrast (referred as Contrast/ Dominance in Table 1) for all their evaluated objects got conclusive results with positive appreciation. Taking pair 6 as shown in Figure 4 for example, the highest percentage was $77 \%$ of the total perceptions voting for image $\mathrm{A}$ as more credible (see Table 1), which applied contrast and dominance by contrast. These perceptions were justified interestingly and unexpectedly in the subjects' comments like:

\section{"More eye catching colour than B" "Attractive logo"}

Similarly, dominance by size was positively and highly perceived, taking pair 2 shown in Figure 5 for example, 97\% of perceptions considered image B as more credible (see Table 1), which had a dominant large image, justifying this as:

"More appealing than A due to its big image"

"Image made B more attractive and interactive"
Table 1. Interview Results

\begin{tabular}{|l|l|l|l|l|l|}
\hline Pair & Relationship & A & B & None & Results \\
\hline 1 & $\begin{array}{l}\text { Contrast / } \\
\text { Dominance }\end{array}$ & $63 \%$ & $30 \%$ & $7 \%$ & A \\
\hline 2 & $\begin{array}{l}\text { Dominance } \\
\text { by size }\end{array}$ & $3 \%$ & $97 \%$ & 0 & B \\
\hline 3 & $\begin{array}{l}\text { Balance } \\
\text { Informal }\end{array}$ & $20 \%$ & $77 \%$ & $3 \%$ & B \\
\hline 4 & Harmony & $37 \%$ & $6 \%$ & $57 \%$ & None \\
\hline 5 & Harmony & $10 \%$ & $17 \%$ & $73 \%$ & None \\
\hline 6 & $\begin{array}{l}\text { Contrast } / \\
\text { Dominance }\end{array}$ & $77 \%$ & $10 \%$ & $13 \%$ & A \\
\hline 7 & $\begin{array}{l}\text { Balance }- \\
\text { Informal }\end{array}$ & $20 \%$ & $6 \%$ & $74 \%$ & None \\
\hline 8 & $\begin{array}{l}\text { Balance }- \\
\text { Formal }\end{array}$ & $20 \%$ & $23 \%$ & $57 \%$ & None \\
\hline 9 & $\begin{array}{l}\text { Balance }- \\
\text { Formal }\end{array}$ & $87 \%$ & $10 \%$ & $3 \%$ & A \\
\hline 10 & $\begin{array}{l}\text { Balance }- \\
\text { Formal }\end{array}$ & $70 \%$ & $0 \%$ & $30 \%$ & A \\
\hline 11 & Harmony & $17 \%$ & $3 \%$ & $80 \%$ & None \\
\hline 12 & Harmony & $17 \%$ & $73 \%$ & $10 \%$ & B \\
\hline 13 & $\begin{array}{l}\text { Dominance } \\
\text { by size }\end{array}$ & $10 \%$ & $90 \%$ & $0 \%$ & B \\
\hline & & & & \\
\hline
\end{tabular}

This reveals that image B catches attention which is, after all, the main aim of dominance. Here, it is important to denote that none of the subjects reported any legibility problem in perceiving and judging stimuli.

From that, it can be concluded that subjects were able to perceive contrast/dominance by contrast and dominance by size as elements that affected their first impressions of credibility, justifying them as attractive and eye catching factors.

Judgments on web credibility on pairs investigating harmony of different colours and balance (formal and informal) were inconclusive for most of the evaluated objects. These unperceived judgments might be excused that the difference between the two images in a pair might not be so easily perceived within 3.42 seconds; it may need more than that time to perceive the difference, especially when considering justifications like these in subject's comments:

\section{"Almost similar" \\ "Difficult to catch a difference" \\ "Fast for assessment"}

This may also indicate that either image in the pair might be credible as both appear similar. Ultimately, 8 out of the 13 results were explicitly conclusive judgments on web credibility on the basis of aesthetics, and four conclusions can be drawn from the interview perceptions:

1. Contrast, dominance by contrast and dominance by size were $100 \%$ conclusively appreciated for all the evaluated objects/ attributes.

2. Balance got conclusive results for some objects/attributes while it was inconclusive for the rest: $33.3 \%$ of the total perceptions were inconclusive for formal balance, and $50 \%$ were inconclusive for informal balance. 


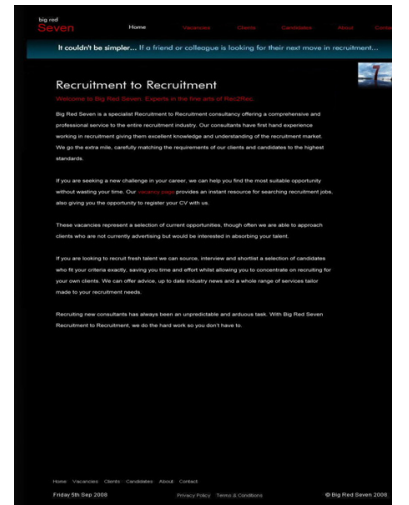

A

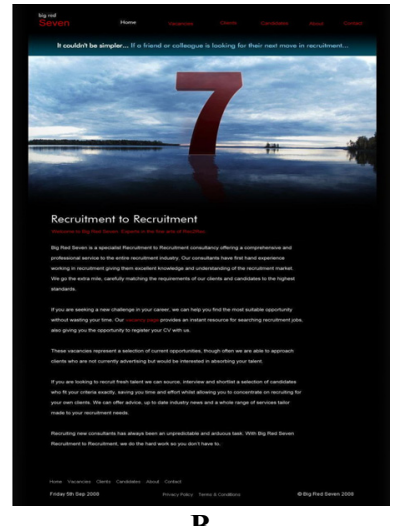

B
Figure 5. Pair 2 Stimuli Investigating Dominance by Size

3. Harmony was inconclusive for $75 \%$ of the total perceptions for some of the evaluated objects/attributes.

4. It is worth mentioning that images suggested by our method as being more aesthetically appealing were either highly appreciated or unperceived. None of them was unappreciated by the subjects which, it can be argued, supports the claims of the method to a large degree.

To ensure precise appreciation for the relationships of balance, harmony, contrast/dominance by contrast and dominance by size suggested by our method, subjects responded to a time free questionnaire after viewing the images, where questions had been developed to ensure an easier understanding by the subjects. As this question which investigates appreciation of harmony:

In a home page, will the harmony between the colours of logo, text, links and background, catch your attention, encourage you to continue searching in that web site and make you decide that this web site is credible? Like this home page for example? (see Figure 6).

$50 \%$ of the responses agreed, while $40 \%$ strongly agreed (Table 2 ). This shows a high appreciation of harmony.

We can draw four conclusions from the results (Table 2):

1. Subjects agreed on the harmony for all evaluated objects/attributes.

2. Subjects agreed on the contrast/dominance by contrast for all the evaluated objects/attributes.

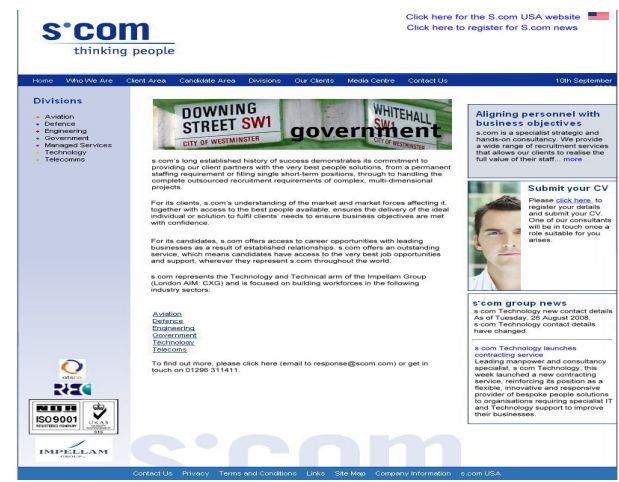

Figure 6. Stimulus Investigating Harmony of Colours
Table 2. Questionnaire Results

\begin{tabular}{|c|c|c|c|c|}
\hline & Harmony & $\begin{array}{c}\text { Contrast/ } \\
\text { Dominance }\end{array}$ & $\begin{array}{c}\text { Dominance } \\
\text { by size }\end{array}$ & Balance \\
\hline $\begin{array}{c}\text { Strongly } \\
\text { disagree }\end{array}$ & $0 \%$ & $0 \%$ & $1 \%$ & $0 \%$ \\
\hline Disagree & $7 \%$ & $13 \%$ & $4 \%$ & $3 \%$ \\
\hline $\begin{array}{c}\text { Neither } \\
\text { agree nor } \\
\text { disagree }\end{array}$ & $3 \%$ & $30 \%$ & $6 \%$ & $3 \%$ \\
\hline Agree & $50 \%$ & $34 \%$ & $44 \%$ & $50 \%$ \\
\hline $\begin{array}{c}\text { Strongly } \\
\text { agree }\end{array}$ & $40 \%$ & $23 \%$ & $45 \%$ & $44 \%$ \\
\hline Results & Agree & Agree & $\begin{array}{c}\text { Strongly } \\
\text { agree }\end{array}$ & Agree \\
\hline
\end{tabular}

3. Subjects strongly agreed on dominance by size for most evaluated objects/attributes.

4. Subjects agreed on balance in its two forms, formal and informal, for all evaluated objects/attributes.

\subsection{Testing}

To test the robustness of our results, we carried out a testing procedure. Testing was carried out with different stimuli, but exactly for the same evaluated objects' attributes and the same procedure as in the original appraisal. It met the perceptions of the original appraisal method as no significant differences were encountered between the two, with some results being even higher in cases.

\subsection{Discussion}

Although the interview results (see Table 1) showed that judging credibility in as fast as 3.42 seconds on an aesthetic basis is valid, and provided evidence that the evaluated relationships in the method were perceived, this study will not consider these perceptions as the actual perceptions for the aesthetic appraisal method. Even though these results fall within the goal of study, 3.42 seconds is a critical amount of time that puts subjects under undue pressure and will, in all probability, not produce clear and complete results in all cases. For example, balance and harmony (Table 1) for some objects gained inconclusive perceptions, while they were highly appreciated when the same images were viewed without time constraint in the questionnaire (Table 2). In fact, during the questionnaire, the subjects were able to decide and give a selection on all the concepts which they were

unable to perceive before, and so the questionnaire's perceptions (see section 3.6 and Table 2) instead will be considered as our conclusions for evaluating the aesthetic factors responsible in judging the credibility of home pages from first impressions. These conclusions can be better illustrated in Figure 7.

In conclusion, the aesthetics appraisal method discovered that 'Unity' can be achieved in a home page by relationships of harmony, balance, contrast/dominance by contrast and dominance by size, all of which were generally highly perceived and appreciated. Making 'Unity' in home page design affects users' judgments on web credibility, as home pages that achieve 'Unity' in their design are considered to be more credible than others that lack 'Unity' in their design. 


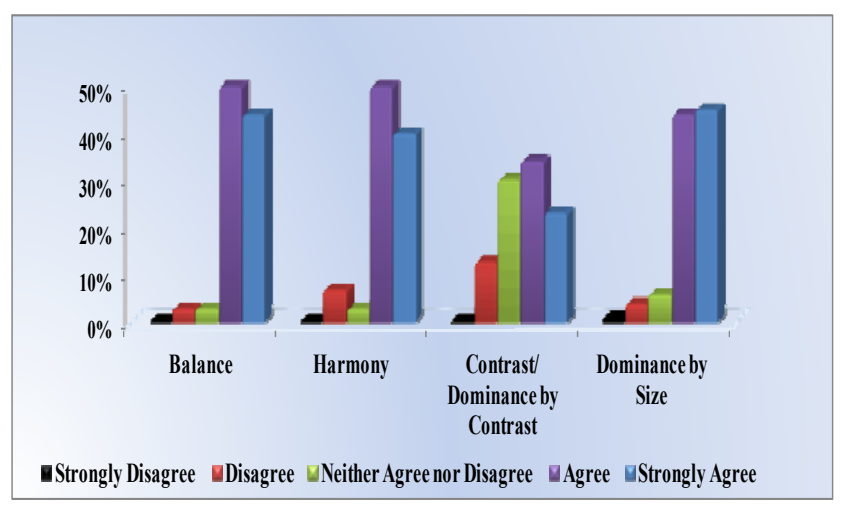

Figure 7. Questionnaire Results

\section{CONCLUIONS}

In this paper, we described a framework to evaluate the effect of web aesthetics factors on instant judgments on web credibility, a task not previously reported. This framework is based on the human foundation that is argued by Gestalt psychology - humans perceive things as whole entities rather than individual elements. This corresponds with a basic and pure design principle - 'Unity', which is responsible for making all components in any artistic composition cooperate to make the composition perceived as a unified attractive unit. The interface of a web page, and ultimately a web site can be considered as an artistic composition, and for that our study suggests that 'Unity' can be applied to achieve a more appealing web interface, and eventually produce better immediate judgments on web credibility. Based on this, we have developed our framework of web aesthetics factors, which consists of pure design concepts called relationships that relate different objects in a web page together. Our framework discusses web factors from a pure design perspective and introduces some new design concepts - identicality, discord and dominance which have not been discussed in previous studies. Ultimately, our framework for web aesthetics factors combines HCI and aesthetic computing together.

Due to human involvement in appraising aesthetics, no systematic method that evaluates web aesthetics was identified through our review. Thus, we developed a systematic method to appraise web aesthetics, which depends on interactive human perceptions in evaluating web aesthetics factors responsible for instant judgment on web credibility. The method depends on our suggested web aesthetics factors framework to evaluate the effect of 'Unity' in a home page design on instant judgments on web site credibility, by achieving relationships of balance, harmony contrast, and dominance. Since we are studying instant judgements on web credibility, we have discussed only the effect of 'Unity' in a home page design rather than the effect of 'Unity' in a whole web site's design.

To identify aesthetic factors responsible for instant judgments on credibility, the method used subjects to evaluate stimuli of recruitment agency web sites, by letting subjects judge credibility within 3.42 seconds only, we found that balance, harmony, contrast and dominance achieve a form of 'Unity' in design that affect users' immediate judgments on web credibility and attract their attention encouraging them to stay in a web site. The more the home page of a web site achieves 'Unity' in its design, the more it is considered to be credible from the first look. Balance and harmony are the minimum requirements to achieve 'Unity' in design; both make pages aesthetically comfortable to the eyes, while contrast and dominance adds attractiveness that catches users' attention.

These findings offer helpful non stifling technical guidelines for novice web designers as affective design factors on credibility. Since web designers are in need for such guidelines [24], to help them in their design and to help a lot of credible web sites to be appealing from the first look to increase their users and expand their business, our findings were presented as tutorials published on line ${ }^{1}$.

Our study aims to enrich the HCI field that lacks studies on web credibility and aesthetics. Plus, it has highlighted how to achieve better interaction between users and web sites which is an essential demand in the HCI field, and, it has focused on the effective role of aesthetics in web design and how influential it is specifically on web credibility, proving that it is not a décor aspect only and promoting the aesthetic computing field.

\section{ACKNOWLEDGMENTS}

Our thanks to Dr.Terry Hinton, Dr. Amy Tan for their guidance during the research phase, Hadeel Albayati for her technical advice and our subjects. All images of web sites used in this study are copyrighted material.

\section{REFERENCES}

[1] Arnheim, R. 1983 Art and visual perception: A psychology of the creative eye. Los Angeles, University of California Press.

[2] Bauerly, M., and Liu, Y. L. 2008. Effects of symmetry and number of compositional elements on interface and design aesthetics. International Journal of Human-Computer Interaction 24, 3 (2004), 275-287.

[3] Bierut, M., Drenttel, W., Heller, S. and Holland, D.K. 1994 Looking Closer: Critical Writings on Graphic Design. New York, Allworth Communications, Inc.

[4] Fishwick, P. 2006 Aesthetic Computing. Cambridge, Massachusetts, London, the MIT Press.

[5] Fogg, B.J., and Tseng, H. 1999. The elements of computer credibility. In Proceedings of the SIGCHI conference on Human factors in computing systems: the $\mathrm{CHI}$ is the limit (Pennsylvania, United States, May 15 - 20, 1999). ACM Press, New York, NY, 80-87.

[6] Fogg, B.J., Soohoo, C., and Danielson, D. 2002. How Do People Evaluate a Web Site's Credibility?: Results from a Large Study. Consumer Reports Webwatch. DOI= http://www.consumerwebwatch.org/dynamic/webcredibility-reports-evaluate-abstract.cfm

[7] Fogg, B.J. 2003. Prominence-interpretation theory: explaining how people assess credibility online. In Proceedings of CHI '03 extended abstracts on Human Factors in Computing Systems (Florida, USA, April 05 10, 2003). ACM Press, New York, NY, 722-723.

[8] ISO (9241-151) 2008 Ergonomics of human-system interaction-Part 151: Guidance on World Wide Web user interface. BSI -British Standards.

[9] Jacobs, M. 2004 Graphic Design Concepts. Third Edition, North Olmsted, OH, Words \& Pictures Publishing.

[10] King, J. 1992 The Art of Mathematics. New York, Plenum Press.

\footnotetext{
${ }^{1}$ www.a-view-webdesign.co.uk
} 
[11] Koffka, K. 1935 Principles of Gestalt Psychology, New York, Harcourt Brace.

[12] Landa, R. 2001 Graphic Design Solutions. Second Edition. South Africa, Stamford, CT: On Word Press.

[13] Lauer, D. A. 1985 Design basics. Belmont, CA, Wadsworth.

[14] Lavie, T., and Tractinsky, N. 2004. Assessing dimensions of perceived visual aesthetics of web sites. International Journal of Human-Computer Studies 60, 3 (Mar. 2004), 269-298.

[15] Lazar, J., Meiselwitz,G., and Feng, J. 2007. Understanding Web Credibility: A Synthesis of the Research Literature. Foundation and Trends in HumanComputer Interaction 1, 2 (2007), 139-202.

[16] Lindgaard, G., and Whitfield, T.W.A. 2004. Integrating aesthetics within an evolutionary and psychological framework. Theoretical Issues in Ergonomics Science 5, 1 (Jan. 2004), 73-90.

[17] Lindgaard, G., Fernandes,G., Dudek, C. and Brown, J. 2006. Attention web designers: you have 50 milliseconds to make a good first impression. Behaviour \& Information Technology 25, 2 (Mar. 2004), 115-126.

[18] Ngo, D.C.L., and Byrne, J.G. 2001. Application of an aesthetic evaluation model to data entry screens Computers In Human Behaviour 17, 2 (Mar. 2001), 149185.

[19] Nielsen, J. 2000 Designing Web Usability. United States of America, New Riders Publishing.

[20] Park, S., Choi, D., and Kim, J. 2005 Visualizing E-Brand Personality: Exploratory Studies on Visual Attributes and
E-Brand Personalities in Korea. International Journal of Human-Computer Interaction, 19, 1(2005), 7-34.

[21] Robins, D., and Holmes, J. 2008. Aesthetics and Credibility in Web Site Design. Information Processing \& Management 44, 1 (Jan. 2008), 386-399.

[22] Schenkamn, B.N., and Jönsson, F. U. 2000. Aesthetics and Preferences of Web Pages. Behaviour and Information Technology 19, 5 (Sep. 2000), 367-377(11).

[23] Shirzad, S.I. 1985 Principles in Art and Architecture. Baghdad, Iraq, Aldar Alarabiya. [Written in Arabic]

[24] Shneiderman, B., 2000. Designing Trust into Online Experiences. Communications of the ACM 43, 12 (Dec. 2000), 57-59.

[25] Shneiderman, B. 2004. Designing for Fun: How Can We Design User Interfaces to Be More Fun? Interactions 11, 5 (Sep. \& Oct. 2004), $48-50$.

[26] Thorlacius, L. 2007. The Role of Aesthetics in Web Design. Nordic Information Center for Media and communication research Nordicom Review 28, 63-76. $\mathrm{DOI}=$ http://www.nordicom.gu.se/common/publ_pdf/247_thorlac ius.pdf

[27] Tidwell, J. 2006 Patterns for effective Interaction Design Designing Interfaces. Sebastopol, CA 95472, O’Reilly Media Inc.

[28] Web Site Optimization 2006. First Impressions Count in Web Design. Websiteoptimization. DOI= http://www.websiteoptimization.com/speed/tweak/blink/

[29] White, A. W. 2002 The Elements of Graphic Design: space, unity, page architecture, and type. New York, Allworth Communications, Inc. 